\title{
PRODUCT CONFIGURATION SYSTEM DEVELOPMENT FOR CAD/CAM SOFTWARE
}

\author{
László Karker $^{a}$, Mátyás Andó $^{b^{*}}$, Jegan Mohan Sudhan Raj $^{b}$ \\ ${ }^{a}$ ELTE, Faculty of Informatics, Savaria Institute of Technology, Mechanical Engineering BSc, IV. year \\ ${ }^{b}$ ELTE, Faculty of Informatics, Savaria Institute of Technology, associate professor
}

\begin{abstract}
The radical development of the industry leads manufacturers to adopt more effective methods to exclude the deficit in their process. The application designed in this research establishes a connection between Autodesk Inventor and Edgecam (Hexagon). In case of the component-group the automatic toolpath generation is efficiently usable even in changing product palette. The perfect CAD model with the suitable toolpath is generated in just 92 seconds. The application takes into account the used technological considerations through the manufacturing. For example, the tool dependent diameter before threading, asymmetric tolerance, chamfer and inner fillet. The program is reliably usable from the first machining because the automatically filled parameters minimizes the possibility of errors. The solution increases the reliability of the quotation (even for ERP systems) because it ensures valid process time and toolset.
\end{abstract}

Keywords: CAM, CAD, Engineer intelligence, Group technology, Optimization

\section{Introduction}

The pretension of the customers changed in the past 10 years over the variability of the products. In this competitive field of manufacturing, it is needed to adapt to the various challenges and provide multiple ranges of product [1]. The high volume low mix (HVLM) production method, which has large volume of products with lower selection is gradually decreasing in recent years [2]. Due to this trend, the manufactures are tend to adopt new business structures, which will enhance their process effectively and economically.

Even still some of the manufactures are following HVLM method. Hence, the 2nd generation massproduction methods were used to minimize the defect in the process. However, in the 3rd generation mass production method (HMLV- high mix low volume), the six sigma and lean manufacturing techniques are not so effective [3].

In the automation of mass production process, due to the longer manufacturing time, specific targeted solutions are to be generated. They had time to experience and even optimize production through the years, so the waste become minimal. However, as a result of the changed conditions, there will be no more opportunities to utilize this strategy. According to automatization and optimization, the process can be divided into 2 parts: the cutting process and the preparing process. In case of a small series batch production, the preparing process is more important than the production process. For example, in a six-piece series, the preparing process starting from the receipt of technical drawing to the beginning of the cutting process consumes much time compared to the machining time [4].

(C) ELTE, Faculty of Informatics, Savaria Institute of Technology, 2020

*Corresponding author: Mátyás Andó, am@inf.elte.hu

https://doi.org/10.37775/EIS.2020.2.5 


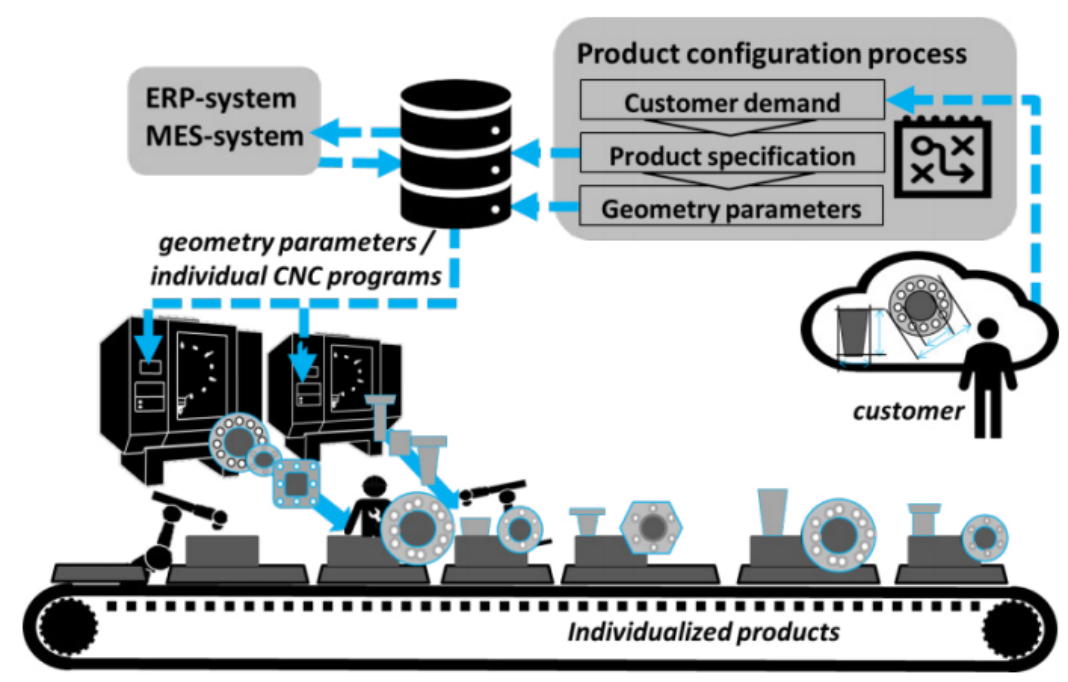

Figure 1. Modern manufacturing system industry 4.0 construction [7]

Following the trends of production, a group technology-based manufacturing concept to start to spread over the past few years [5]. The group technology has a great past and it constantly develops $[2,6]$. The grouping of the parts leads to more efficient manufacturing in case of variable and low range productions (HMLV) [3]. Fig. 1 shows a modern structures, which uses a flexible manufacturing system with group-technology, also uses Industry 4.0 elements for their cutting systems [7].

The CNC program is generated step by step, in case of group-technology. Most of the manufacturers generates a so-called G-code manually and the others create individual programs for every product using the CAM system [7]. The modern CAD/CAM systems enhances the effectiveness of these processes while neglecting the repetitive tasks [8]. Recently, every CAD system has some kind of CAM surface, however, the CAD developers may not offer the optimal CAM system for a specific production [9].

In the case of modern automatized systems, the product configuration systems are not commonly used. However, it is proved that using this system, the time required for starting the manufacturing process is drastically reduced [7]. The product configuration system on its graphical surface ensures the quick and efficient modification of the product range. By utilizing these tools, the CAD model and the manufacturing program can be modified for every individual orders. Integrating the data provided by other suppliers (e.g. cutting tool supplier) into a flexible manufacturing systems process is a hard task, even though the CAD and CAM software were developed by the same IT company. When CAD and CAM software developed from different company, the data integration becomes more challenging.

The product configuration system developed in this research is intended to offer a possible solution to these problems. By utilizing this the time required to initiate the machining process can be minimized. It can fix the errors of the unsuitable CAD models and correct the errors from the simplified technical drawings.

\section{Material and method}

Autodesk Inventor Professional 2018 is used to generate the geometrical model, the same procedure can also be done in the 2020 version. Due to its drawing functions and customizable modeling the 2018 version is preferred in this research. In the case of CAM system, the Edgecam 2020 Software was used due to its inherent flexibility in transferring information between the CAM system and its 
strategic module. The graphic programming platform is versatile and the modifications are easier. The CAM system also offers an adaptive tool database, which generates the cutting parameters based on the machining environment.

The programming was generated using C\# coding on WPF (Windows Presentation Foundation) using Microsoft Visual Studio. The WPF uses the XAML as surface (frontend) programming language and the $\mathrm{C \#}$ as a background (backend) programming language [10]. The created program also generates JavaScript-based program, which is accessible by the CAM system and it processes the data of the thread calculator into the cycle.

\section{Creating a correct CAD model}

Creating a CAD model is an important step to initiate the manufacturing process. The initial step in developing individual and low range products starts from the quotation. The ERP system generates an accurate quote, when the customers' demands such one, as shown in Fig. 1. The cost factor can also be calculated and integrated into the CAD system, based on the parameters of the product and machine. In constructing some of the complex shapes, there are often asymmetrical tolerances, fits, threads, undefined edge on the parts. This should be considered in the CAD modelling phase, otherwise it will lead to a defective part production. If the CAD model is not precise, it may lead to miscalculation in the quotation, which causes financial loss.

It is a common practice to use the ISO 2768 standard in manufacturing, which provides tolerances for linear and angular dimensions without individual tolerance indications. The chosen group sign influences the size of the tolerance. Because the tolerances are symmetric, as for the modelling it does not cause any change. Some of the asymmetric tolerances and fits (ISO 286) information are missing in the model. Hence, the CAD systems generate the model for the basic nominal dimensions. This results to defective part or the settings are to be updated each time for the current interfaces, which requires huge investment in manpower and time.

The improper tooling leads to waste production. Hence, before initiating the production, the tolerances of the tools used for production must be altered with those specified in the drawing. This is one of the most common mistakes in the manufacturing holes. Also, it is an additional problem if there is a thread in the hole, because the core hole and the chamfer are modelled inaccurately. The insert which used to create the inner edges is especially critical. If the radius of the tool nose is larger than specified, then the scrap can arise. According to the ISO 13715 standard, the edge undercut or passing are not included in the CAD model. Hence, the proper selection and modelling of the components is a part of the manufacturing process.

The tool manufactures recommendations are to be considered to develop suitable products, especially in the case of threaded parts. Most of the manufacturers use a full profile insert to generate threaded parts. While creating the model they do not consider the specific cylindrical surface on which the threads are to be generated. This surface are to be generated with a tolerance, so that the diameter of the cylindrical surface will be larger than the nominal size. If this tolerance is not provided in the threaded section the manufactured part may not perform well. It is necessary to define the dimensions within the tolerance limits while programming. The manufacturing program should be created to the middle of the tolerance zone. By following this way, the process can be maintained at a greater accuracy in a long run. This is due to the fact that the actual size alters between the upper and lower tolerance limits, which will reduce the defective parts. The Inventor also provides the ability to specify asymmetric tolerances as well as fits for parametric modelled parts. Also, the model size can be set to generate automatically to the mean of the specified asymmetric fits and tolerances. 


\section{Basics of the process}

In our earlier research [11], a prefabricated material and tool database was created using Edgecam platform. It was tested for the parameter selection in order to confirm the applicability of the database-based technology. Based on these results the development phase is carried out. The operation and structure of the developed product configuration system is shown in Fig. 2.

In Fig. 2, the developed product configuration system is marked in yellow, and the modules which the system is directly connected are marked in orange. The access of the product configuration system is initiated on receiving the order for the product with individual dimensions and thread properties. During the process, the initial step is the calculation of thread in the system. After entering the thread type on the ordered part, the data and tolerances required for machining the thread are displayed in the calculator. The calculator accesses the Inventor database to calculate and retrieve data for that type of thread. Then the shape features of the ordered product are checked and from the menu item corresponding to the part in the configuration system was selected. On selecting from the menu, the parameterized model is displayed in the Inventor, where the changes made are recorded here. From the same menu the parameterized model can be modified to the appropriate size of the product. The thread properties calculated with the calculator are given as inputs in the modification fields. The modification overwrites the model control file attached to the CAD model. It is also used to recheck the accuracy of the dimensions on the part. Once the code is modified, this feature also serves as an effective size control option. A macro can be created in Inventor in order to change the dimensions of the model automatically, which was assigned to the parameterized parts. This macro runs automatically on the logic panel in the Inventor on opening the parts file.

From the model settings, the application generates a JavaScript program. It then fills in the thread machining cycle with data in the CAM system. This adaptively generated program is highlighted in orange in Fig. 2 and is represented as thread parameters. To test the system a parametric component-group was created as shown in Fig. 3. Components of the part-groups are represented in the Fig. 3 as A - step shaft, B - step shaft with groove, C - step shaft with thread, D - step shaft

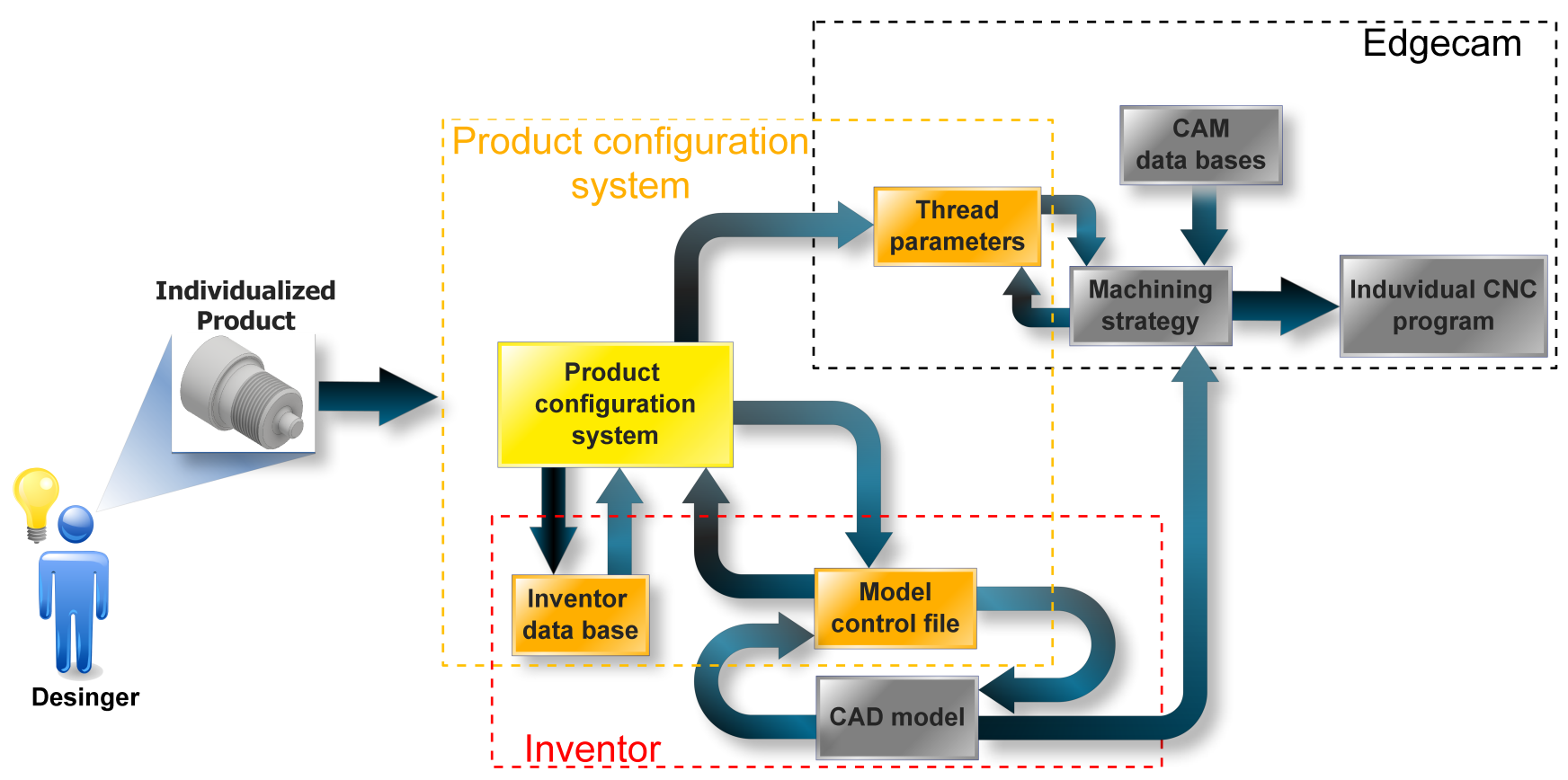

Figure 2. Structure and operation of the product configuration system 

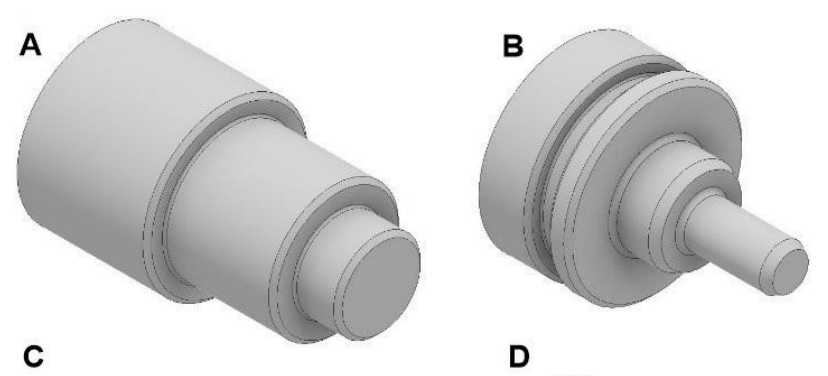

C

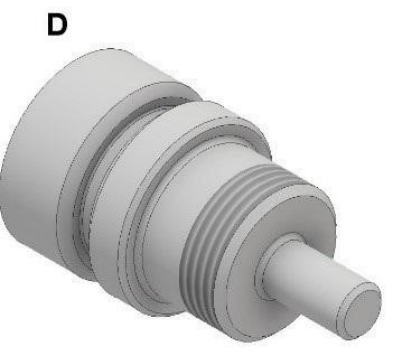

Figure 3. The component-group created for testing

with groove and thread. The dimensions and tolerances of the component can be changed freely. Furthermore, to test the operation a rudimentary machining strategy was developed in Edgecam to check the operation of the process (Fig. 4).

\section{Results}

From this newly generated product configuration system, the CAD models of the components can be converted into individual product versions according to customer needs. By using the group technology in the application, which allows to manage the manufactured portfolio quickly and efficiently in the graphical interface. The configuration interface is shown in Fig. 5. It also provides the modification of additional geometric features of the model in the graphical interface system. It automatically changes the modeling environment as a result of modification. The accurate CAD model is created automatically. It is clearly seen from the CAD model it is made within the tolerance limits. The design of the system is much more ergonomic and transparent and it provides faster handling compared to the manual modification.

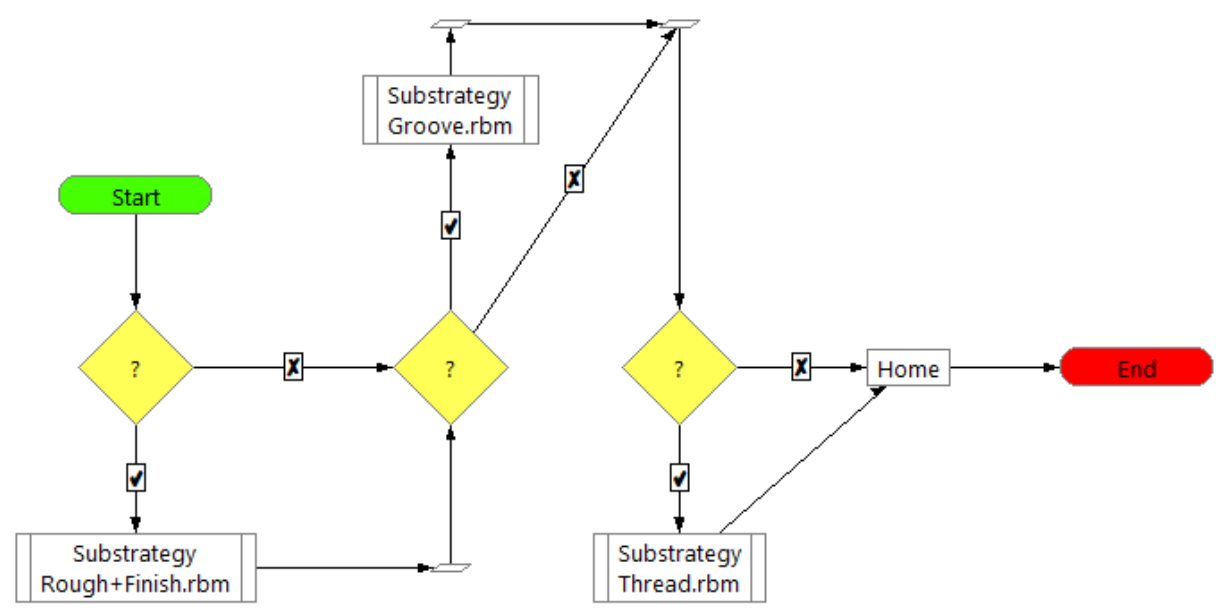

Figure 4. CAM machining strategy used for testing 


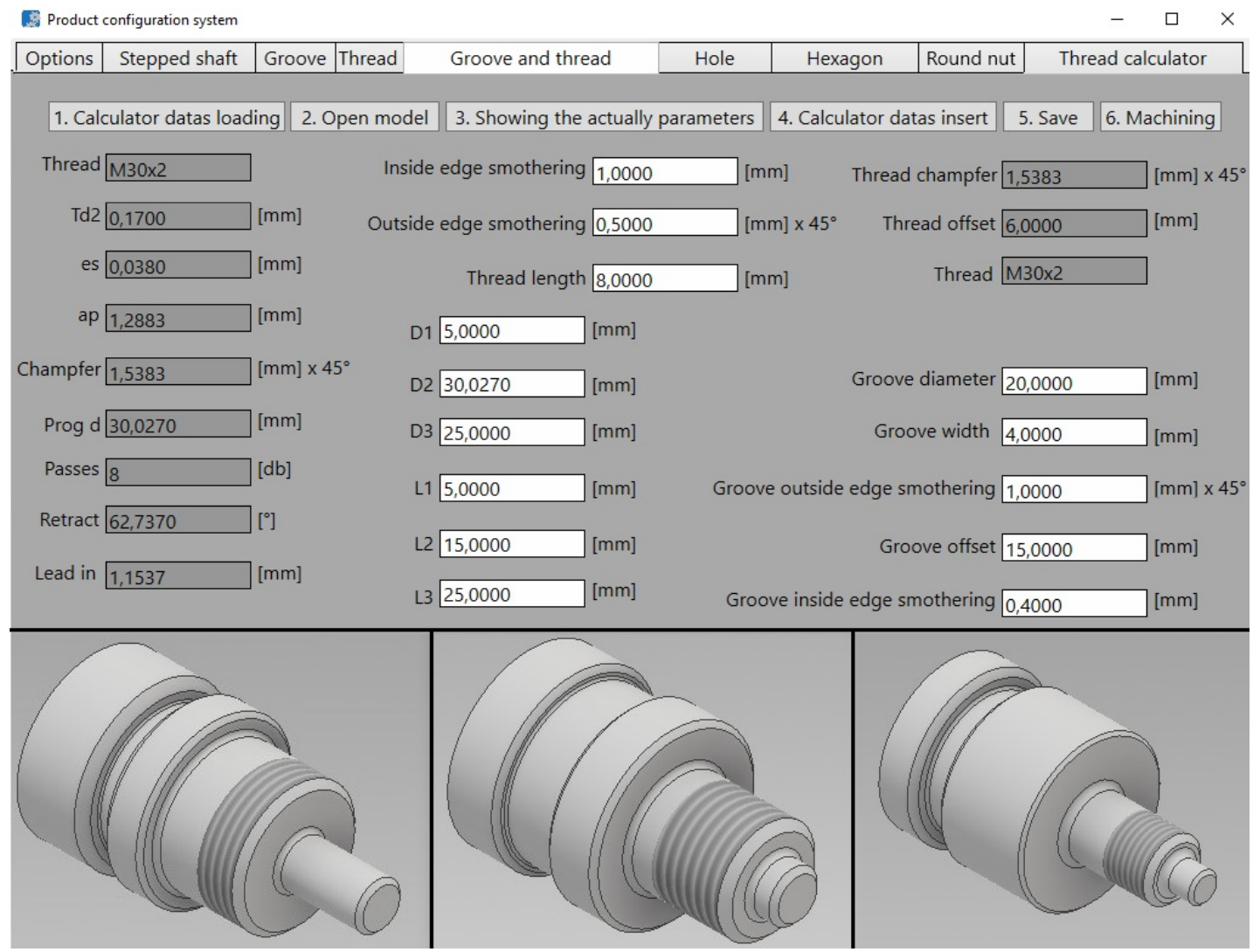

Figure 5. The configuration surface

In the Invertor system the thread diameters can only be assigned based on the thread type from the developer's data. However, when machining a thread the geometrical dimensions and the thread run out depends on the tool and the machine. The newly developed system addresses this problem. In the testing demonstration that the CAD model and the machining program data calculated with the thread calculator was used. The automatic data transfer greatly increases the speed of production preparation. In addition, we exclude several possible errors that could result from calculations and incorrect settings. The application effectively overcomes the limitations between CAD/CAM systems from different developers and also considers tool manufacturer recommendations. The application has been developed to use a full profile insert. The CAD model is automatically converted accordingly so that the thread on the manufactured product is error free. Fig. 6 shows the CAM paths generated by the system.

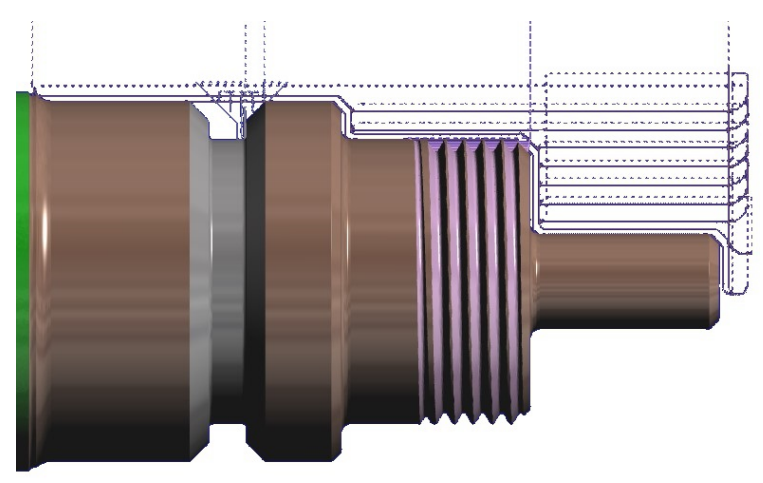

Figure 6. The generated toolpaths 
An experienced user can create toolpaths in 90 seconds using this application with pre-opened software. The machining time, that the Edgecam automatically calculated, was 7 minutes 33 seconds. Within this stipulated time, the accurate CAD model is generated. Then the selection of appropriate tools and inserts needed for production happened and the exact machining time was determined. Thus, this software generate quotes reliably for individual product variants with more accuracy in a shorter time.

\section{Conclusions}

In this paper a newly developed product configuration system was introduced. The time required to prepare for production was drastically reduced to less than 2 minutes. This concept of connecting CAD and CAM systems can be used effectively to serve the current market conditions where the variety of products produced in small quantities. In group-technology-based production, the developed method can be effectively used for programing CNC machines, as the developed program generates accurate CAD model. With the built-in offline thread calculator and export function, the final CNC program can also be created in the CAM software automatically. With this method, quotations can be made based on the exact machining time.

\section{Acknowledgement}

The project with contract number ED_18-1-2019-0030 (Application-specific high-reliability IT solutions theme area) was implemented with the support of the National Research Development and Innovation Fund, with the support of the Thematic Excellence Program.

\section{References}

[1] A. Angelopoulou, K. Mykoniatis, N.R. Boyapati, Industry 4.0: The use of simulation for human reliability assessment, Procedia Manufacturing 42, 2020, pp. 296-301. CrossRef

[2] I. Ham, E.V. Goncalves, C.P. Han , An Integrated Approach to Group Technology Part Family Data Base Design Based on Artificial Intelligence Techniques, CIRP Annals 37(1), 1988, pp. 433-437. CrossRef

[3] Patrick de Vos, Group Technology: Operational Excellence in the Industry 4.0 Era, Seco Tools AB, Björnbacksvägen 2, 73782 Fagersta Sweden, 2018, url

[4] Patrick de Vos, Steps 6-10 To Peak Performance and Productivity, Seco Tools AB, Björnbacksvägen 2, 73782 Fagersta Sweden, 2020, url

[5] D. Lukic, A. Antic, S. Borojevic, M. Jocanovic, I. Kuric, Evaluation of the technological effects of application of the FMS elements, IOP Conference Series: Materials Science and Engineering. IOP Publishing Ltd 749 012018, 2020, CrossRef

[6] R.G. Askin, C.R. Standridge, Modeling and Analysis of Manufacturing Systems, John Wiley \& Sons, 1993, ISBN: 978-0-471-51418-3, pp. 155-156.

[7] C. Schaede, S. Seifermann, J. Metternich, Automated generation of CNC programs for manufacturing of individualized products, Procedia CIRP 72, 2018, pp. 1251-1257. CrossRef

[8] T. Dodok, N. Čuboňová, D. Wiecek, Optimization of machining processes preparation with usage of Strategy Manager, MATEC Web of Conferences 244(26):02004, 2018, CrossRef 
[9] T. Dodok, N. Čuboňová, M. Císara, I. Kurica, I. Zajačkoa, Utilization of strategies to generate and optimize machining sequences in CAD/CAM, Procedia Engineering 192, 2017, pp. 113-118. CrossRef

[10] M. Chand, What is WPF, Scharpcorner blog, url

[11] L. Karker, M. Andó, Adatbázis alapú technológiai paraméter választás CAM rendszerekben, Mérnöki és Informatikai Megoldások|Engineering and IT Solutions I., 2020, pp. 27-33. CrossRef 